\title{
Effects of feed form and particle size on growth performance, nutrient digestibility, carcass characteristics, and gastric health in growing-finishing pigs
}

\author{
Yun Yeong Jo ${ }^{1}$, Myung Jae Choi $^{2}$, Woo Lim Chung ${ }^{2}$, Jin Su Hong ${ }^{2}$, Jong Seon Lim ${ }^{1}$, and Yoo Yong Kim ${ }^{2, \star}$
}

\author{
* Corresponding Author: Yoo Yong Kim \\ Tel: +82-2-880-4801, Fax: +82-2-878-5839, \\ E-mail: yooykim@snu.ac.kr \\ ${ }^{1}$ Feed Innovation Center, Sunjin Company \\ Limited, Seoul 05372, Korea \\ ${ }^{2}$ Research Institute of Agriculture and Life \\ Sciences, Seoul National University, Seou \\ 08826, Korea \\ ORCID \\ Yun Yeong Jo \\ https://orcid.org/0000-0003-0969-9877 \\ Myung Jae Choi \\ https://orcid.org/0000-0003-2690-8714 \\ Woo Lim Chung \\ https://orcid.org/0000-0003-1724-9358 \\ Jin Su Hong \\ https://orcid.org/0000-0002-3401-3024 \\ Jong Seon Lim \\ https://orcid.org/0000-0001-7601-3623 \\ Yoo Yong Kim \\ https://orcid.org/0000-0001-8121-3291
}

Submitted Nov 16, 2020; Revised Dec 19, 2020; Accepted Jan 12, 2021
Objective: This study was conducted to evaluate the effects of feed processing and particle size on growth performance, nutrient digestibility, carcass characteristics, and gastric health in growing-finishing pigs.

Methods: A total of 360 growing pigs $(22.64 \pm 0.014 \mathrm{~kg}$ initial body weight [BW]) were allocated to 1 of 6 treatments with 6 replicates by BW and sex, and 10 pigs were housed in one pen in a randomized complete block design. The BW and feed intake were recorded to calculate growth performance. For the digestibility trial, a total of 24 barrows with an initial BW of $33.65 \pm 0.372 \mathrm{~kg}$ were split into 6 treatments with a completely randomized design. Dietary treatments were designed by a $2 \times 3$ factorial arrangement of treatments based on two main factors, particle size $(600,750,900 \mu \mathrm{m})$ and feed form (mash and pellet) of diet. Experimental diets were formulated to contain the requirements of the NRC (2012).

Results: The BW and average daily gain were not changed by dietary treatments, and the feed intake of finishing pigs (wks 6 to 12) was increased when the pigs were fed a mash diet $(p<0.05)$. For the overall period, the feed efficiency of pigs was improved with the pellet diet $(p<0.01)$ and reduced particle size $(p<0.05)$. The pellet diet had effects on increasing crude fat digestibility $(p<0.01)$ relative to a mash diet, but there was no considerable change in dry matter and crude protein digestibilities by dietary treatments. In the evaluation of gastric health, a trend for an increased incidence of keratinization in the esophageal region was observed as particle size decreased $(\mathrm{p}=0.07)$.

Conclusion: Feed efficiency could be improved by pellet diet and reduced particle size. Nutrient digestibility, carcass characteristics, and gastric health were not affected by feed form, and particle size ranged from 600 to $900 \mu \mathrm{m}$.

Keywords: Feed Processing; Pellet Diet; Particle Size; Growth Performance; Nutrient Digestibility; Gastric Health

\section{INTRODUCTION}

The physical properties of the diet are important factors for determining animal performance, and optimal particle size has been a popular research topic based on this background $[1,2]$. Reduced particle size may increase the surface area for enzyme digestion, and there are many results describing the positive effects of reduced particle size on the nutrient digestibility of pigs $[3,4]$. Apparent total tract digestibility (ATTD) of starch was improved with decreased particle size from 920 to $580 \mu \mathrm{m}$ [5], and reduced particle size had effects on increasing the ATTD of gross energy and crude protein (CP) [6]. Although reduced particle size has many positive effects, it may lead to increased production cost and decreased feed productivity. Furthermore, the responses of different particle sizes were inconsistent in several studies because of different feed intakes [3], altered inci- 
dences of gastric ulcers $[7,8]$, and various environmental conditions [9]. Therefore, a study evaluating the optimal particle size is clearly needed to improve the growth of pigs with acceptable production costs.

Pelleting a corn-soybean meal diet had positive effects on improving growth performance, nutrient digestibility, and feed efficiency $[10,11]$. Ulens et al [12] demonstrated that the feed efficiency of pigs fed a pellet diet was increased relative to those fed a mash diet, and Steidinger et al [13] found that pelleting feed ingredients improved the feed intake of weaning pigs. The major reason for these responses was improved gelatinization of the starch fraction in feed ingredients [10]. Although there were many findings associated with the effects of pellet diet on pigs, limited information is available for the interaction between feed form and particle size of feed ingredients.

Feed form and particle size of diet are dominant factors for determining production cost, but it is difficult to implement optimal standard, because of inconsistent results from previous studies. In this case, the accumulation of meaningful researches and the revalidation process are important to find a conclusion. Thus, this study was conducted to determine the effects of feed processing and particle size on growth performance, nutrient digestibility, carcass characteristics, and gastric health in growing-finishing pigs.

\section{MATERIALS AND METHODS}

\section{Animal care}

All experiments with animals were conducted based on the standard of the Institutional Animal Care and Use Committee provided by Seoul National University (SNUIACUC; SNU171203-03).

\section{Animals, housing, and diets}

A total of 360 growing pigs ([Yorkshire $\times$ Landrace $] \times$ Duroc; $22.64 \pm 0.014 \mathrm{~kg}$ initial body weight $[\mathrm{BW}])$ were used for a 12-wk growth trial and allotted to each of 6 treatments in 6 replicates based on BW and sex in a randomized complete block design. Each pen had 10 pigs and was equipped with half-slotted concrete floors $(1.60 \times 3.00 \mathrm{~m})$, water nipples, and a feeder to provide water and feed with ad libitum access. Room temperature was controlled stably at $24^{\circ} \mathrm{C}$ for the 6-wk growing period and $22^{\circ} \mathrm{C}$ for the 6-wk finishing period. The BW and feed intake were recorded at the $0,3 \mathrm{rd}, 6 \mathrm{th}$, 10 th, and 12 th wks to calculate the average daily gain (ADG), average daily feed intake (ADFI) and gain-to-feed ratio (G/F ratio).

Dietary treatments were designed by a $2 \times 3$ factorial arrangement of treatments, and the main factors were particle size $(600,750,900 \mu \mathrm{m})$ and feed form (mash and pellet) of the diet. Corn and soybean meal were major ingredients in the experimental diets. Grower diets contained 3,300 kcal of metabolizable energy (ME)/kg, $15.00 \% \mathrm{CP}, 1.11 \%$ total lysine, $0.66 \%$ total $\mathrm{Ca}$, and $0.56 \%$ total $\mathrm{P}$, and finisher diets contained 3,275 kcal of ME/kg, 14.00\% CP, 1.01\% total lysine, $0.52 \% \mathrm{Ca}$, and $0.47 \%$ total $\mathrm{P}$, respectively. All other nutrients met or exceeded the requirements of NRC (2012) [14], and the formula and chemical composition of the experimental diets are presented in Table 1.

\section{Production conditions for the experimental diet}

The experimental diet was ground by a hammer mill (ANDRITZ Feed \& Biofuel, Denmark) equipped with screen sizes of 3.6, 2.6, and $1.6 \mathrm{~mm}$. The average production volume was 4 tons, and the hammer mill screen was changed to control the particle size. The pelleted diets were produced by a 400 -horsepower pellet mill (7730-8, CPM, Denmark, 80-mm-thick die with 4.2-mm-diameter holes), and steam was used for conditioning the diets to $75^{\circ} \mathrm{C}$ before the pelleting process. The temperature of pellet processing was not exceed $80^{\circ} \mathrm{C}$ with 6.5 to $7.8 \mathrm{kWh}$ for 60 minutes.

Table 1. The formulas and chemical compositions of the growing and finishing diets

\begin{tabular}{lcc}
\hline Items & Growing diet (\%) & Finishing diet (\%) \\
\hline Ingredients (\%) & & \\
Corn & 40.57 & 45.81 \\
Wheat & 35.00 & 35.00 \\
Soybean meal & 16.70 & 13.66 \\
Mixed animal fat & 3.84 & 2.30 \\
Mono-di calcium phosphate & 1.24 & 0.82 \\
Limestone & 0.76 & 0.68 \\
Salt & 0.40 & 0.40 \\
L-lysine HCl (78\%) & 0.57 & 0.55 \\
DL-methionine (99\%) & 0.20 & 0.18 \\
L-tryptophan (99\%) & 0.05 & 0.05 \\
L-threonine (99\%) & 0.23 & 0.22 \\
Vitamin Mix ${ }^{1)}$ & 0.05 & 0.05 \\
Mineral Mix & 0.34 & 0.23 \\
Choline Cl (50\%) & 0.05 & 0.05 \\
Total & 100.00 & 100.00 \\
Chemical composition ${ }^{3)}$ & & \\
ME (kcal/kg) & $3,300.00$ & $3,275.00$ \\
CP (\%) & 15.00 & 14.00 \\
Lys (\%) & 1.11 & 1.01 \\
Met (\%) & 0.43 & 0.39 \\
Ca (\%) & 0.66 & 0.52 \\
Total P (\%) & 0.56 & 0.47 \\
\hline
\end{tabular}

$\mathrm{ME}$, metabolizable energy; $\mathrm{CP}$, crude protein.

1) Provided per kg of diet: vitamin $A, 12,000 \mathrm{IU}$; vitamin $\mathrm{D}_{3}, 2,400 \mathrm{IU}$; vitamin $\mathrm{E}, 10 \mathrm{IU}$; vitamin $\mathrm{K}, 5.6 \mathrm{mg}$; vitamin $\mathrm{B}_{2}, 4 \mathrm{mg}$; vitamin $\mathrm{B}_{6}, 2 \mathrm{mg}$; vitamin $B_{12}, 40 \mu$; pantothenic acid, 16 mg; biotin, $100 \mu$; niacin, 20 mg; folic acid, $1 \mathrm{mg}$.

2) Provided per kg of diet: Fe, 65 mg; Mn, 30 mg; Zn, 30 mg; Cu, 50 mg; Se, $500 \mu \mathrm{g} ; \mathrm{l}, 1.24 \mathrm{mg}$.

${ }^{3)}$ Calculated values. 


\section{Digestibility trial}

For evaluating total tract digestibility, a total of 24 barrows ([Yorkshire $\times$ Landrace] $\times$ Duroc; $33.65 \pm 0.372 \mathrm{~kg}$ initial BW) were split into 6 treatments with a completely randomized design. Diets were fed to pigs twice a day at 0700 and 1900 with ad libitum access to water according to the rate of 2.0 times the maintenance requirement for ME (106 kcal of ME per kg of $\mathrm{BW}^{0.75}$; NRC) [14] based on the initial BW of pigs.

Fecal samples were collected 5 days after 5 days of adaptation period, and chromic oxide and ferric oxide were used as initial and end markers, respectively. Collected excreta were frozen immediately at $-20^{\circ} \mathrm{C}$ for the collection period, dried $\left(60^{\circ} \mathrm{C}, 72 \mathrm{~h}\right)$ in an air-drying oven, and ground $(5-\mathrm{mm}$ screen, Wiley mill) for chemical analysis at the end of the trial. Urine samples were also collected daily in a plastic container with $50 \mathrm{~mL}$ of $10 \% \mathrm{H}_{2} \mathrm{SO}_{4}$ to avoid evaporation of ammonia from urine, and glass wool was used as a filter to remove foreign materials. Individual collected urine was massed up to 4,000 $\mathrm{mL}$ with water and mixed evenly. The representative samples were collected in $50-\mathrm{mL}$ conical tubes and frozen at $-20^{\circ} \mathrm{C}$ for nitrogen retention analysis.

\section{Chemical analysis}

Experimental diets and fecal samples were analyzed for dry matter (DM; method 934.01), CP (method 990.03), and ether extract (method $920.39 \mathrm{~A}$ ). In addition, diets were used for analyzing crude fiber (method 978.10), ash (method 942.05),
Ca (method 965.14/985.01), and P (method 965.17/985.01) by AOAC method [15]. The starch contents of the diets were determined by the polarimetric method according to the Commission Directive 1999/79/EC, and the degree of gelatinization was measured by a glucose analyzer (Model 2700, YSI, Yellow Springs, OH, USA). The chemical composition of the analyzed diets is shown in Table 2.

\section{Carcass characteristics}

Thirty six finishing pigs ( 6 pigs for each treatment) were selected and slaughtered to measure the carcass weight, percentage carcass yield and backfat thickness. Carcass yield was calculated by dividing the carcass weight at the abattoir by the live weight at the farm before transport to the abattoir. Backfat thickness was measured between the 11th and 12th points located vertically with the dorsal midline.

\section{Gastric health}

Stomach samples were collected from individual pigs for carcass characteristics during the evisceration process and used for determining ulcer and keratinization scores by the method of De Jong [16]. Keratinization scores were assigned on a scale from 1 to 4 , with 1 being normal or no keratinization of the esophageal region; 2 being keratin covering $<25 \%$ of the esophageal region; 3 being keratin covering $25 \%$ to $75 \%$ of the esophageal region; and 4 being keratin covering $>75 \%$ of the esophageal region. The visual criterion for the

Table 2. Proximate compositions (\%) of the growing and finishing diets ${ }^{1)}$

\begin{tabular}{|c|c|c|c|c|c|c|c|}
\hline \multirow{2}{*}{ Items } & \multirow{2}{*}{$\begin{array}{r}\text { Feed form } \\
\text { Particle size }(\mu \mathrm{m})\end{array}$} & \multicolumn{3}{|c|}{ Mash } & \multicolumn{3}{|c|}{ Pellet } \\
\hline & & 600 & 750 & 900 & 600 & 750 & 900 \\
\hline \multicolumn{8}{|l|}{ Growing diet } \\
\hline Moisture & & 11.45 & 11.51 & 11.53 & 11.15 & 11.77 & 12.25 \\
\hline Crude protein & & 15.03 & 14.81 & 14.52 & 14.49 & 14.67 & 14.83 \\
\hline Crude fat & & 5.50 & 6.18 & 5.76 & 6.36 & 6.07 & 5.87 \\
\hline Crude fiber & & 2.61 & 2.43 & 2.38 & 2.62 & 2.88 & 2.50 \\
\hline Crude ash & & 4.15 & 4.12 & 4.13 & 4.14 & 4.31 & 4.18 \\
\hline $\mathrm{Ca}$ & & 0.66 & 0.66 & 0.64 & 0.64 & 0.66 & 0.62 \\
\hline Total P & & 0.57 & 0.56 & 0.55 & 0.59 & 0.58 & 0.57 \\
\hline Starch & & 48.72 & 48.00 & 48.82 & 49.13 & 47.96 & 47.31 \\
\hline Gelatinization & & 23.21 & 24.04 & 24.95 & 24.45 & 24.75 & 24.67 \\
\hline \multicolumn{8}{|l|}{ Finishing diet } \\
\hline Moisture & & 11.44 & 11.56 & 11.95 & 12.12 & 13.48 & 12.12 \\
\hline Crude protein & & 13.81 & 13.98 & 14.10 & 13.56 & 14.05 & 13.56 \\
\hline Crude fat & & 4.38 & 4.49 & 4.45 & 4.95 & 4.75 & 4.95 \\
\hline Crude fiber & & 2.41 & 2.56 & 2.79 & 2.33 & 1.91 & 2.33 \\
\hline Crude ash & & 3.73 & 3.80 & 3.65 & 3.56 & 3.67 & 3.56 \\
\hline $\mathrm{Ca}$ & & 0.52 & 0.53 & 0.52 & 0.53 & 0.55 & 0.53 \\
\hline Total P & & 0.49 & 0.46 & 0.45 & 0.45 & 0.43 & 0.45 \\
\hline Starch & & 51.47 & 51.39 & 51.66 & 51.62 & 49.17 & 51.62 \\
\hline Gelatinization & & 21.92 & 21.68 & 23.91 & 29.63 & 29.16 & 29.63 \\
\hline
\end{tabular}

Analyzed values. 
keratinization score is shown in Figure 1. Ulcer scores were also assigned on a scale from 1 to 4 , with 1 being no ulcers present; 2 being ulceration affecting $<25 \%$ of the esophageal region; 3 ulceration affecting $25 \%$ to $75 \%$ of the esophageal region; and 4 being ulceration affecting $>75 \%$ of the esophageal region.

\section{Statistical analysis}

All collected data were compared by least squares mean comparisons with the general linear model procedure of SAS (SAS Institute Inc., Cary, NC, USA,). As an experimental unit, individual pens were applied for analyzing performance data, whereas individual pigs were applied for analyzing nutrient digestibility, carcass characteristics, incidence of ulcers and keratinization in the stomach. The experimental unit was analyzed based on $2 \times 3$ factorial arrangements, and 2 main factors were feed form and particle size. Based on least significant-difference test, the differences were declared significant at $\mathrm{p}<0.05$ or highly significant at $\mathrm{p}<0.01$, and the determination of tendency for all analyses was $p>0.05$ and $\mathrm{p}<0.10$.

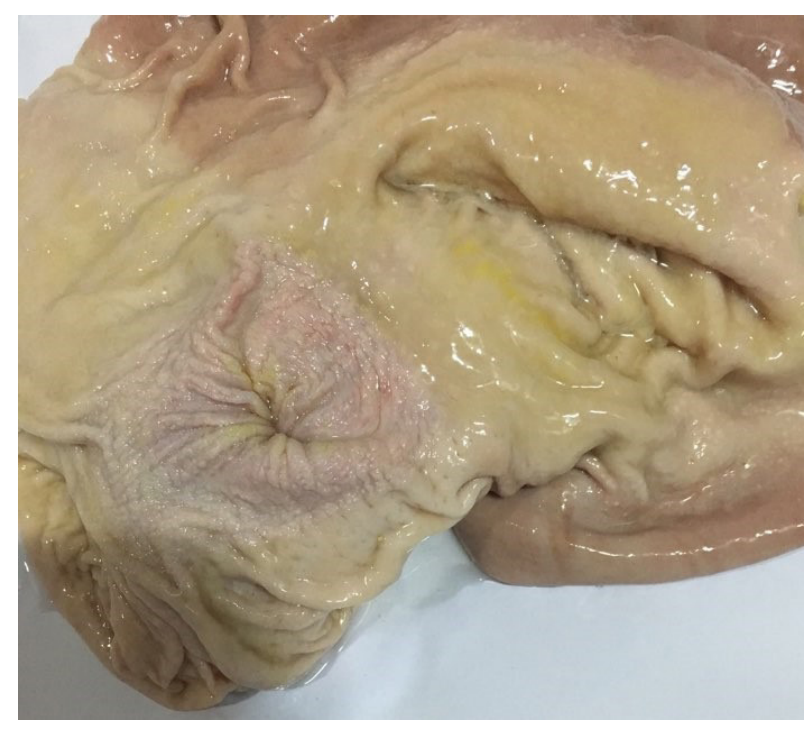

(A)

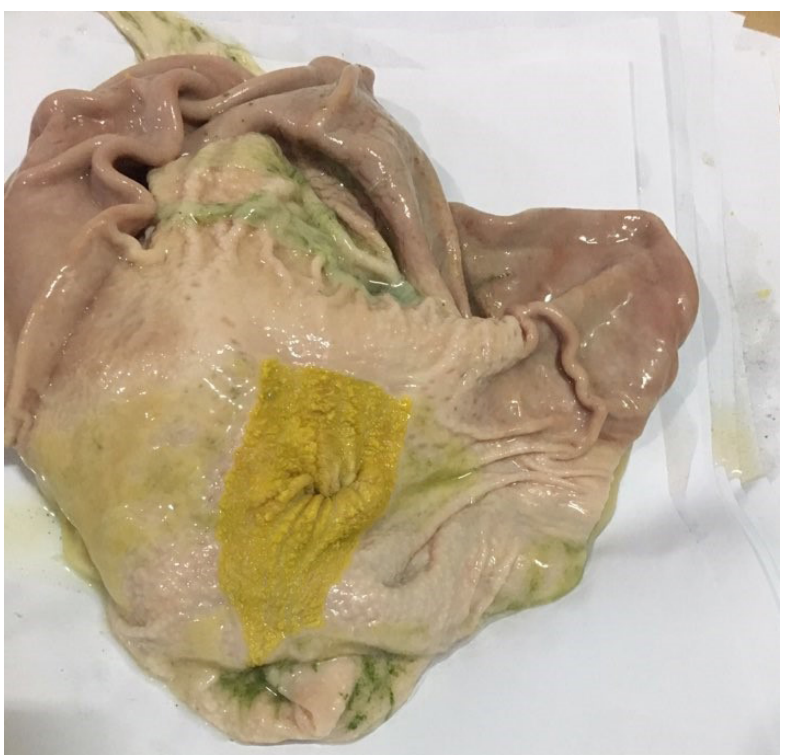

(C)

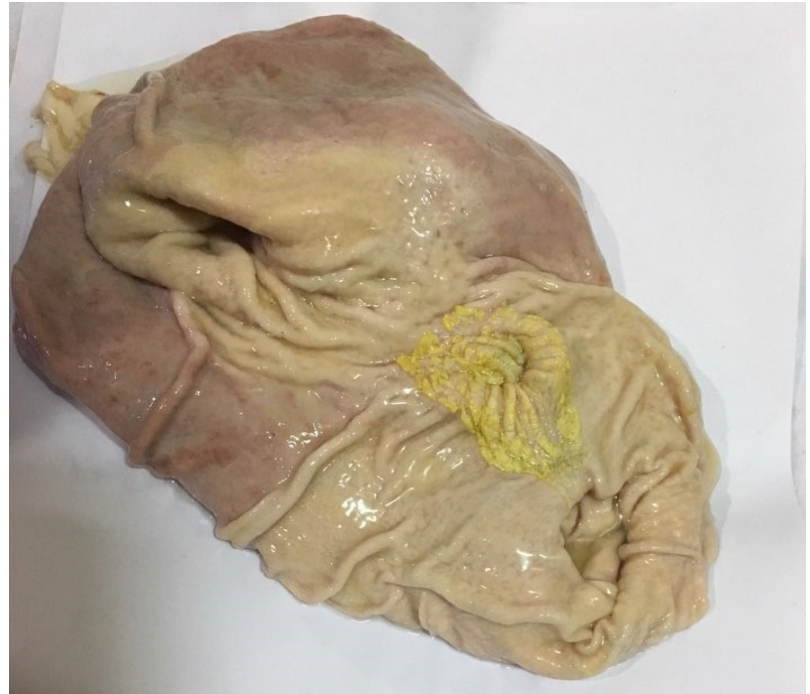

(B)

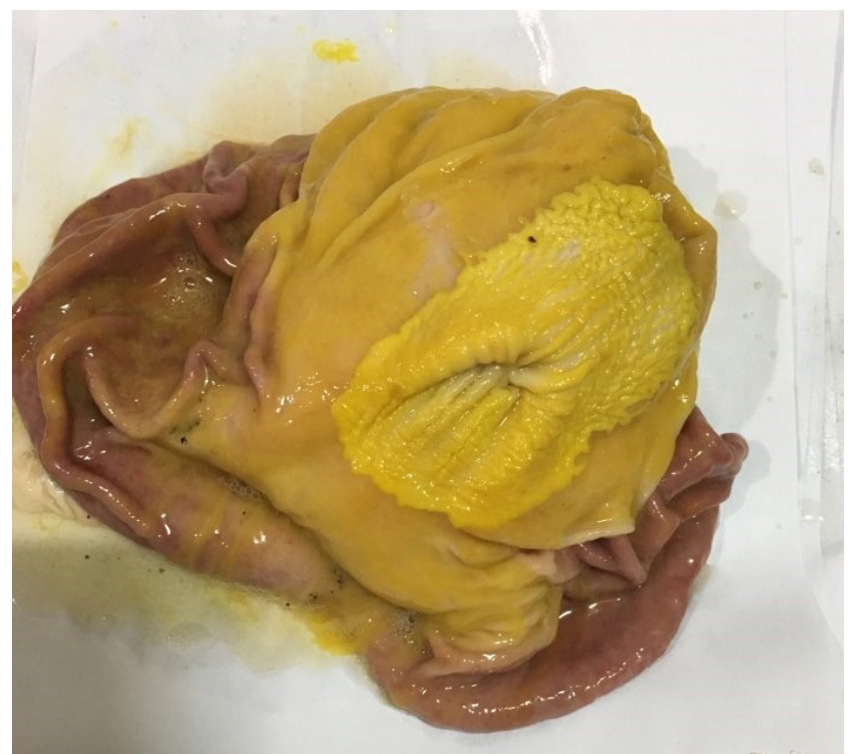

(D)

Figure 1. Keratinization incidence scoring standard. The (A) represents keratinization score 1 being normal or no keratinization of the esophageal region; (B) represents keratinization score 2 being keratin covering $<25 \%$ of the esophageal region; (C) represents keratinization score 3 being keratin covering $25 \%$ to $75 \%$ of the esophageal region; and (D) represents keratinization score 4 being keratin covering $>75 \%$ of the esophageal region. 


\section{RESULTS}

\section{Growth performance}

The effect of feed form and particle size on the growth performance of growing and finishing pigs is presented in Table 3. During the whole experimental period, there was no significant difference in BW and ADG among all dietary treatments. The finishing pigs fed the mash diet had higher ADFI than those fed the pellet diet for wks 7 to 10 ( $p<0.05$ ), 11 to $12(\mathrm{p}<0.05)$, and 7 to $12(\mathrm{p}<0.05)$; however, different feed forms had no effect on the ADFI of growing pigs. For the overall period, there was a tendency for improved ADFI when the pigs were fed the mash diet $(p=0.09)$.

The feed efficiency of pigs was consistently shown to be improved when the pigs were fed the pellet diet, regardless of the experimental period (wks 0 to $3, \mathrm{p}<0.01 ; 0$ to $6, \mathrm{p}<0.01$; 7 to $10, \mathrm{p}<0.05 ; 11$ to $12, \mathrm{p}<0.05 ; 7$ to $12, \mathrm{p}<0.01 ; 0$ to $12, \mathrm{p}<$ $0.01)$. Decreasing particle size also improved the feed efficiency of finishing pigs at wks 7 to 10 ( $\mathrm{p}<0.01), 7$ to 12 ( $\mathrm{p}<0.05$ ), and 0 to $12(\mathrm{p}<0.05)$. For all parameters of the growth trial, there was no interaction between the particle size and feed form.

\section{Nutrient digestibility}

Feeding the pellet diet improved crude fat digestibility $(\mathrm{p}<$ 0.01 ) relative to the mash diet (Table 4). However, the total tract digestibilities of $\mathrm{DM}$ and $\mathrm{CP}$ were not affected by different feed forms and particle sizes.

\section{Carcass characteristics}

The live weight, carcass yield and backfat thickness were measured to evaluate treatment effects on carcass characteristics (Table 5). For all parameters, there was no considerable change by dietary treatments.

\section{Gastric health}

The effects of feed form and particle size on the ulceration and keratinization scores of finishing pigs are presented in

Table 3. The effect of feed form and particle size on the growth performance of growing and finishing pigs

\begin{tabular}{|c|c|c|c|c|c|c|c|c|c|}
\hline \multirow{2}{*}{ Items } & \multicolumn{2}{|c|}{ Feed form } & \multicolumn{3}{|c|}{ Particle size $(\mu \mathrm{m})$} & \multirow{2}{*}{ SEM } & \multicolumn{3}{|c|}{ p-value ${ }^{1)}$} \\
\hline & Mash & Pellet & 600 & 750 & 900 & & $\mathbf{F}$ & PS & FxPS \\
\hline \multicolumn{10}{|c|}{ Body weight (kg) } \\
\hline Initial & 22.64 & 22.64 & 22.63 & 22.64 & 22.65 & 0.580 & 0.67 & 0.99 & 0.84 \\
\hline $3 w k$ & 37.70 & 38.69 & 38.62 & 38.35 & 37.62 & 1.072 & 0.97 & 0.94 & 0.97 \\
\hline $6 w k$ & 57.56 & 58.22 & 58.33 & 57.96 & 57.38 & 1.187 & 0.81 & 0.97 & 0.80 \\
\hline $10 w k$ & 85.58 & 86.37 & 87.62 & 86.30 & 84.01 & 1.356 & 0.91 & 0.62 & 0.82 \\
\hline 12 wk & 100.09 & 100.99 & 101.71 & 101.14 & 98.79 & 1.411 & 0.98 & 0.73 & 0.93 \\
\hline \multicolumn{10}{|l|}{ ADG $(g)$} \\
\hline $0-3 w k$ & 717 & 765 & 762 & 749 & 713 & 25.2 & 0.59 & 0.70 & 0.86 \\
\hline 4-6 wk & 946 & 930 & 939 & 934 & 941 & 14.0 & 0.24 & 0.93 & 0.17 \\
\hline $0-6 w k$ & 831 & 847 & 850 & 841 & 827 & 18.7 & 0.63 & 0.58 & 0.36 \\
\hline 7-10 wk & 1,001 & 999 & 1,039 & 1,013 & 952 & 13.0 & 0.86 & 0.03 & 0.93 \\
\hline $11-12$ wk & 1,037 & 1,044 & 1,007 & 1,060 & 1,056 & 19.9 & 0.66 & 0.53 & 0.40 \\
\hline 7-12 wk & 1,013 & 1,015 & 1,027 & 1,029 & 986 & 10.0 & 0.66 & 0.17 & 0.75 \\
\hline $0-12 w k$ & 922 & 933 & 942 & 934 & 907 & 10.8 & 0.81 & 0.42 & 0.95 \\
\hline \multicolumn{10}{|l|}{ ADFI (g) } \\
\hline $0-3 w k$ & 1,345 & 1,319 & 1,344 & 1,338 & 1,314 & 43.6 & 0.52 & 0.97 & 0.90 \\
\hline 4-6 wk & 1,936 & 1,830 & 1,893 & 1,854 & 1,903 & 42.8 & 0.10 & 0.84 & 0.53 \\
\hline $0-6 w k$ & 1,640 & 1,574 & 1,618 & 1,596 & 1,608 & 41.8 & 0.25 & 0.98 & 0.74 \\
\hline 7-10 wk & 2,625 & 2,491 & 2,523 & 2,552 & 2,600 & 33.0 & 0.04 & 0.48 & 0.19 \\
\hline $11-12$ wk & 2,576 & 2,444 & 2,480 & 2,576 & 2,475 & 36.3 & 0.04 & 0.74 & 0.51 \\
\hline $7-12$ wk & 2,609 & 2,469 & 2,508 & 2,550 & 2,559 & 31.5 & 0.03 & 0.67 & 0.52 \\
\hline $0-12 w k$ & 2,125 & 2,022 & 2,064 & 2,073 & 2,084 & 34.3 & 0.09 & 0.93 & 0.66 \\
\hline \multicolumn{10}{|l|}{ G:F ratio } \\
\hline $0-3$ wk & 0.533 & 0.581 & 0.568 & 0.561 & 0.542 & 0.071 & $<0.01$ & 0.11 & 0.90 \\
\hline 4-6 wk & 0.493 & 0.517 & 0.508 & 0.510 & 0.499 & 0.080 & 0.13 & 0.83 & 0.53 \\
\hline $0-6 w k$ & 0.510 & 0.544 & 0.533 & 0.532 & 0.517 & 0.058 & $<0.01$ & 0.30 & 0.68 \\
\hline 7-10 wk & 0.383 & 0.403 & 0.413 & 0.398 & 0.368 & 0.063 & 0.04 & $<0.01$ & 0.28 \\
\hline $11-12$ wk & 0.402 & 0.431 & 0.407 & 0.414 & 0.429 & 0.082 & 0.03 & 0.66 & 0.30 \\
\hline $7-12 w k$ & 0.389 & 0.412 & 0.411 & 0.405 & 0.387 & 0.050 & $<0.01$ & 0.04 & 0.16 \\
\hline 0-12 wk & 0.435 & 0.463 & 0.459 & 0.453 & 0.437 & 0.043 & $<0.01$ & 0.01 & 0.28 \\
\hline
\end{tabular}

SEM, standard error of mean; ADG, average daily gain; ADFI, average daily feed intake; G:F ratio, gain-to-feed ratio

${ }^{1)} \mathrm{F}$, feed form; PS, particle size. 
Table 4. The effect of feed form and particle size on the total collection digestibility of growing pigs ${ }^{1)}$

\begin{tabular}{|c|c|c|c|c|c|c|c|c|c|}
\hline \multirow{2}{*}{ Items } & \multicolumn{2}{|c|}{ Feed form } & \multicolumn{3}{|c|}{ Particle size $(\mu \mathrm{m})$} & \multirow{2}{*}{ SEM } & \multicolumn{3}{|c|}{ p-value ${ }^{2)}$} \\
\hline & Mash & Pellet & 600 & 750 & 900 & & $\mathbf{F}$ & PS & F×PS \\
\hline \multicolumn{10}{|c|}{ Nutrient digestibility (\%) } \\
\hline Dry matter & 95.00 & 95.14 & 94.91 & 95.26 & 95.04 & 0.09 & 0.42 & 0.25 & 0.21 \\
\hline Crude protein & 94.52 & 94.16 & 94.21 & 94.56 & 94.26 & 0.14 & 0.19 & 0.53 & 0.32 \\
\hline Crude fat & 91.57 & 93.70 & 92.55 & 92.99 & 92.37 & 0.31 & $<0.01$ & 0.38 & 0.29 \\
\hline \multicolumn{10}{|c|}{ Nitrogen retention $(\mathrm{g} / \mathrm{d})$} \\
\hline $\mathrm{N}$ intake & 29.15 & 29.15 & 29.15 & 29.15 & 29.15 & - & - & - & - \\
\hline Fecal N & 1.61 & 1.69 & 1.66 & 1.57 & 1.71 & 0.04 & 0.28 & 0.37 & 0.16 \\
\hline Urinary N & 1.22 & 1.17 & 1.20 & 1.23 & 1.14 & 0.19 & 0.16 & 0.14 & 0.63 \\
\hline $\mathrm{N}$ retention ${ }^{3)}$ & 26.32 & 26.29 & 26.28 & 26.34 & 26.29 & 0.04 & 0.68 & 0.81 & 0.26 \\
\hline
\end{tabular}

SEM, standard error of the mean.

1) A total of 24 growing pigs were fed an average initial body weight of $33.65 \pm 0.372 \mathrm{~kg}$

2) $F$, feed form; $P S$, particle size.

${ }^{3)} \mathrm{N}$ retention $=\mathrm{N}$ intake - fecal $\mathrm{N}-$ urinary $\mathrm{N}$.

Table 5. The effect of feed form and particle size on carcass characteristics of finishing pigs

\begin{tabular}{|c|c|c|c|c|c|c|c|c|c|}
\hline \multirow{2}{*}{ Item } & \multicolumn{2}{|c|}{ Feed form } & \multicolumn{3}{|c|}{ Particle size $(\mu \mathrm{m})$} & \multirow{2}{*}{ SEM } & \multicolumn{3}{|c|}{ p-value ${ }^{1)}$} \\
\hline & Mash & Pellet & 600 & 750 & 900 & & $\mathbf{F}$ & PS & FxPS \\
\hline Live weight $(\mathrm{kg})$ & 111.2 & 112.0 & 111.8 & 111.4 & 111.4 & 1.30 & 0.77 & 0.96 & 0.67 \\
\hline Carcass yield (\%) & 77.0 & 76.8 & 77.0 & 76.8 & 76.9 & 0.05 & 0.22 & 0.69 & 0.68 \\
\hline Back fat $P_{2}(\mathrm{~mm})$ & 23.5 & 24.3 & 23.5 & 24.2 & 23.8 & 0.94 & 0.64 & 0.98 & 0.38 \\
\hline
\end{tabular}

SEM, standard error of mean.

${ }^{1)} \mathrm{F}$, feed form; PS, particle size.

Table 6. Because of the well-managed environment, there were no pigs with ulceration problems, and dietary feed form had no significant difference on keratinization of the esophageal region. However, a tendency for an increased incidence of keratinization was observed as particle size decreased $(\mathrm{p}=$ 0.07 ). There was no considerable interaction between particle size and feed form.

\section{DISCUSSION}

Comparing pellet and mash diets, many studies have described decreased amounts of feed waste when a pellet diet was provided to the pigs $[17,18]$. For feed consumption, improved intake of weanling pigs with pellet diet was observed
[13], but the response was inconsistent for finishing pigs [18]. Different responses of feed intake by feed form could be induced by environmental conditions and the age of animals [19]. In a well-managed environment, animals would have maximum feed intake, and it is difficult to show treatment effects. Then, changing feed waste by different feed forms could have more effects on recorded feed intake than true feed intake. In this experiment, pigs showed high feed intake during the entire experimental period compared with the normal standard curve for feed intake, and the feed intake was improved in the mash diet, especially for the finishing phase. This result probably resulted from the reduced feed waste of the pellet diet; however, further study is needed to determine the clear reason for the increased feed intake of

Table 6. The effect of feed form and particle size on ulceration and keratinization of finishing pigs

\begin{tabular}{|c|c|c|c|c|c|c|c|c|c|}
\hline \multirow{2}{*}{ Items } & \multicolumn{2}{|c|}{ Feed form } & \multicolumn{3}{|c|}{ Particle size $(\mu \mathrm{m})$} & \multirow{2}{*}{ SEM } & \multicolumn{3}{|c|}{ p-value ${ }^{1)}$} \\
\hline & Mash & Pellet & 600 & 750 & 900 & & $F$ & PS & FXPS \\
\hline$\overline{\text { Keratinizaition }^{2}}$ & 1.83 & 1.72 & 2.25 & 1.75 & 1.34 & 0.170 & 0.66 & 0.07 & 0.23 \\
\hline
\end{tabular}

SEM, standard error of mean.

${ }^{1)} \mathrm{F}$, feed form; $P S$, particle size.

2) 1 being normal or no keratinization of the esophageal region; 2 being keratin covering $<25 \%$ of the esophageal region; 3 being keratin covering $25 \%$ to

$75 \%$ of the esophageal region; and 4 being keratin covering $>75 \%$ of the esophageal region.

${ }^{3)}$ Ulcer scores were also assigned on a scale from 1 to 4 with 1 being no ulcers present; 2 being ulceration affecting <25\% of the esophageal region; 3

ulceration affecting $25 \%$ to $75 \%$ of the esophageal region; and 4 being ulceration affecting $>75 \%$ of the esophageal region. 
finishing pigs by the mash diet. Different feed intake by various particle sizes was observed in many studies, but the response was not consistent $[4,20]$. In this experiment, different particle sizes exerted no considerable change on feed intake, which means that there is no negative effect on feed intake if the diet is ground below $900 \mu \mathrm{m}$.

Generally, it is well known that the pelleting process improves the starch digestibility of cereal grains due to the increased gelatinization degree of starch $[1,2,10]$. There were several findings for an improved feed conversion ratio ranging from $4 \%$ to $12 \%$ by applying a pellet diet $[11,21]$. In this trial, an improved G/F ratio was observed in pigs fed a pellet diet during the whole experimental period, in agreement with previous findings. Reduced feed waste by applying a pellet diet could also have an effect on improving feed efficiency, aligning with the results of feed intake. Particle size reduction had positive effects on the feed efficiency of swine in previous studies [3,22]. Ohh et al [23] reported that a fine grinding process for corn and sorghum could improve feed efficiency in the starter period, and Wondra et al [24] found that decreasing the particle size of corn resulted in an $8 \%$ improvement of feed efficiency in the growing period (47.8 kg of initial BW). In the present study, the pigs fed diets with a particle size of $900 \mu \mathrm{m}$ showed a lower G/F ratio than those fed diets with particle sizes of 600 and $750 \mu \mathrm{m}$, indicating that a reduced particle size below $750 \mu \mathrm{m}$ could improve feed efficiency in both pellet and mash diets.

Pelleting often resulted in improved ADG and feed efficiency compared with mash diet, and it was derived from improved energy digestibility and reduced feed intake $[1,2$, $12,25]$. Reduced particle size may improve enzyme surface reactions and increase digestibility of nutrients [2,3]. However, these responses of growth could be inconsistent due to changed digestibility by feed intake and environmental conditions [9]. In this trial, the pigs fed a pellet diet with reduced particle size showed numerically higher ADG than other treatments, with a similar trend as in previous studies, but there was no significant difference.

To evaluate the effects of dietary treatments on a total collection digestibility of growing pigs were analyzed. Several findings demonstrated that pelleting could improve digestibilities of $\mathrm{DM}, \mathrm{N}$, and energy ranging from $5 \%$ to $8 \%$ [24], and increased AID of indispensable AA by application of a pellet diet was also observed [26]. In previous studies of positive effects, the main reason for improved digestibility by pelleting was increased starch gelatinization and changed protein confirmation by the steam conditioning process; however, some findings demonstrated inconsistent results with $\mathrm{N}$ and AA digestibility because of different pelleting and steam conditions $[27,28]$. In this study, crude fat digestibility was improved by pelleting, in agreement with previous findings [10], but the digestibilities for DM and
$\mathrm{CP}$ were not affected by dietary treatments. In the digestibility trial of this study, a restricted feeding method was applied, and the pigs were housed in a well-managed environment. Consequently, the DM and CP digestibilities of pigs fed mash and pellet diets were all over $94 \%$, and it was difficult to differentiate treatment effects.

Increased nutrient digestibility by reduced particle size has been demonstrated consistently in previous studies [29, 30 ], and a popular approach for this improvement is prolonged passage rate of digesta and increased surface area for enzyme reaction. Appel [31] reported that the flowability of digesta was reduced as particle size decreased, and Jensen and Becker [10] found that reduced particle size may lead to improved energy digestibility. However, the nutrient digestibilities of DM, CP, and crude fiber were not changed by different particle sizes in this trial, which means that particle sizes between 600 and $900 \mu \mathrm{m}$ show no difference in the digestibility of growing pigs with restricted feeding methods. In the growth trial, ad libitum access to feed was applied, and an improved G/F ratio was observed by reduced particle size. These different feeding programs could induce different digestibilities for various parameters, and further experiments are needed to validate the effects of the feeding program on the response of particle size.

Few studies have validated the interaction between feed form and particle size [12,24]. To improve the quality and hardness of pellets, a reduced particle size is essential; however, the standard particle size for the pelleting process was inconsistent because of different production conditions and diet compositions. In the present study, an interaction response between the two factors was not observed in all parameters, and these results suggested that the effects of pellets on growth and digestibility were not changed with particle size ranging from 600 to $900 \mu \mathrm{m}$.

Potter et al [18] demonstrated that carcass yield and backfat thickness after slaughter were increased when pigs were fed a pellet diet relative to those fed a mash diet, and the main reason for this change was improved energy digestibility and reduced organ weight. However, the pigs fed the pellet diet had no effect on carcass traits in this trial. In some cases, carcass yield was increased by reduced particle size because of decreased organ weight [4]. However, a significant effect of carcass characteristics by different particle sizes was not observed in this experiment, and different particle size ranges would be one of the reasons for this difference. In the study of Rojas and Stein [4], the particle size ranged from 339 to $865 \mu \mathrm{m}$, relatively lower than $600 \mu \mathrm{m}$, and this result indicated that particle size up to $600 \mu \mathrm{m}$ had no effects on the carcass characteristics of finishing pigs.

The esophageal region is the most risky region for developing gastric ulcers, and an increased incidence of gastric ulcers by reduced particle size was reported by previous 
studies $[7,8]$. However, those responses could be inconsistent based on other factors, such as management methods and type of housing $[32,33]$. In the present study, there were no pigs with gastric ulcer problems but there was a tendency for increased keratinization score as particle size increased $(p=0.07)$. Development of ulcer in stomach is derived from keratinization of esophageal region. Frequent peristalsis of gut stimulates the hardening of the epithelium cells and that region of keratinization was stained by bile from small intestine. That region absorbs stains and the color is changed to yellow. Swelling and erosion the area of keratinization is the following step of ulceration [34].

For the overall period, the feed efficiency of pigs was improved with the pellet diet and the average particle size of $600 \mu \mathrm{m}$. Pelleting had no effects on DM and CP digestibilities but resulted in improved crude fat digestibility relative to the mash diet. There was no considerable change in carcass characteristics by dietary treatments, but a trend for increasing incidence of keratinization of the esophageal region was observed with reduced particle size.

\section{CONFLICT OF INTEREST}

We certify that there is no conflict of interest with any financial organization regarding the material discussed in the manuscript. Jo YY and Lim JS are employees of Sunjin Company Limited.

\section{ACKNOWLEDGMENTS}

This research was supported by the BK21 Plus project of the National Research Foundation of Korea Grant (Seoul, Korea) and funded by Sunjin Company Limited (Icheon, Korea).

\section{REFERENCES}

1. Attia YA, El-Tahawy WS, Abd El-Hamid AEE, Hassan SS, Nizza A, El-Kelaway MI. Effect of phytase with or without multienzyme supplementation on performance and nutrient digestibility of young broiler chicks fed mash or crumble diets. Ital J Anim Sci 2012;11:e56. https://doi.org/10.4081/ijas.2012. e56

2. Attia YA, El-Tahawy WS, Abd El-Hamid AEE, et al. Effect of feed form, pellet diameter and enzymes supplementation on growth performance and nutrient digestibility of broiler during days 21-37 of age. Arch Anim Breed 2014;57:34. https:// doi.org/10.7482/0003-9438-57-034

3. Mavromichalis I, Hancock JD, Senne BW, et al. Enzyme supplementation and particle size of wheat in diets for nursery and finishing pigs. J Anim Sci 2000;78:3086-95. https:// doi.org/10.2527/2000.78123086x

4. Rojas OJ, Stein HH. Effects of reducing the particle size of corn grain on the concentration of digestible and metabolizable energy and on the digestibility of energy and nutrients in corn grain fed to growing pigs. Livest Sci 2015;181:187-93. https://doi.org/10.1016/j.livsci.2015.09.013

5. Kim JC, Mullan BP, Pluske JR. A comparison of waxy versus non-waxy wheats in diets for weaner pigs: effects of particle size, enzyme supplementation, and collection day on total tract apparent digestibility and pig performance. Anim Feed Sci Technol 2005;120:51-65. https://doi.org/10.1016/j. anifeedsci.2005.01.004

6. Oryschak MA, Simmins PH, Zijlstra RT. Effect of dietary particle size and carbohydrase and/or phytase supplementation on nitrogen and phosphorus excretion of grower pigs. Can J Anim Sci 2002;82:533-40. https://doi.org/10.4141/ A02-016

7. Mahan DC, Pickett RA, Perry TW, Curtin TM, Featherston WR, Beeson WM. Influence of various nutritional factors and physical form of feed on esophagogastric ulcers in swine. J Anim Sci 1966;25:1019-23. https://doi.org/10.2527/jas1966. 2541019x

8. Maxwell CV, Reimann EM, Hoekstra WG, Kowalczyk T, Benevenga NJ, Grummer RH. Effect of dietary particle size on lesion development and on the contents of various regions of the swine stomach. J Anim Sci 1970;30:911-22. https://doi. org/10.2527/jas1970.306911x

9. Rojas OJ, Stein HH. Processing of ingredients and diets and effects on nutritional value for pigs. J Anim Sci Biotechnol 2017;8:48. https://doi.org/10.1186/s40104-017-0177-1

10. Jensen AH, Becker DE. Effect of pelleting diets and dietary components on the performance of young pigs. J Anim Sci 1965;24:392-7. https://doi.org/10.2527/jas1965.242392x

11. Lewis LL, Stark CR, Fahrenholz AC, Goncalves MAD, DeRouchey JM, Jones CK. Effects of pelleting conditioner retention time on nursery pig growth performance. J Anim Sci 2015;93:1098-102. https://doi.org/10.2527/jas.2014-8072

12. Ulens T, Demeyer P, Ampe B, Van Langenhove H, Millet S. Effect of grinding intensity and pelleting of the diet on indoor particulate matter concentrations and growth performance of weanling pigs. J Anim Sci 2015;93:627-36. https:/doi.org/ 10.2527/jas.2014-8362

13. Steidinger MU, Goodband RD, Tokach MD, et al. Effects of pelleting and pellet conditioning temperatures on weanling pig performance. J Anim Sci 2000;78:3014-8. https://doi.org/ $10.2527 / 2000.78123014 x$

14. Committee on Nutrient Requirements of Swine, National Research Council. Nutrient requirements of swine. 11th ed. Washington, DC, USA: National Academy Press; 2012.

15. Latimer GW. Official methods of analysis of AOAC International. 19th ed. Gaithersburg, MD, USA: AOAC International; 2012.

16. De Jong J. Feed processing challenges facing the swine industry [dissertation]. Manhattan, KS, USA: Kansas State University; 
2015.

17. Nir I, Hillel R, Ptichi I, Shefet G. Effect of particle size on performance: 3. Grinding pelleting interactions. Poult Sci 1995;74:771-83. https://doi.org/10.3382/ps.0740771

18. Potter ML, Tokach MD, DeRouchey JM, Goodband RD, Nelssen JL, Dritz SS. Effects of meal or pellet diet form on finishing pig performance and carcass characteristics. Manhattan, KS, USA: Kansas State University; 2009. https:/doi. org/10.4148/2378-5977.6789

19. Patience JF. Feed efficiency in swine. Wageningen, Netherlands: Wageningen Academic Publishers; 2012.

20. Seerley RW, Vandergrift WL, Hale OM. Effect of particle size of wheat on performance of nursery, growing and finishing pigs. J Anim Sci 1988;66:2484-9. https://doi.org/10.2527/ jas1988.66102484x

21. Paulk CB, Hancock JD. Effects of an abrupt change between diet form on growth performance of finishing pigs. Anim Feed Sci Technol 2016;211:132-6. https://doi.org/10.1016/ j.anifeedsci.2015.10.017

22. Goodband RD, Hines RH. The effect of barley particle size on starter and finishing pig performance. J Anim Sci 1987; 65:317.

23. Ohh SJ, Allee GL, Behnke KC, Deyoe CW. Effect of particle size of corn and sorghum grain on performance and digestibility of nutrients for weaned pigs. J Anim Sci 1983;57(Suppl 1):260.

24. Wondra KJ, Hancock JD, Behnke KC, Hines RH, Stark CR. Effects of particle size and pelleting on growth performance, nutrient digestibility, and stomach morphology in finishing pigs. J Anim Sci 1995;73:757-63. https://doi.org/10.2527/ 1995.733757x

25. Overholt MF, Lowell JE, Arkfeld EK, et al. Effects of pelleting diets without or with distillers' dried grains with solubles on growth performance, carcass characteristics, and gastrointestinal weights of growing-finishing barrows and gilts. J Anim Sci 2016;94:2172-83. https://doi.org/10.2527/jas.20150202
26. Rojas OJ, Vinyeta E, Stein HH. Effects of pelleting, extrusion, or extrusion and pelleting on energy and nutrient digestibility in diets containing different levels of fiber and fed to growing pigs. J Anim Sci 2016;94:1951-60. https://doi.org/ 10.2527/jas.2015-0137

27. Schell TC, Van Heugten E. The effect of pellet quality on growth performance of grower pigs. J Anim Sci 1998;76(Suppl 1):185.

28. Attia YA, El-Tahawy WS, Abd El-Hamid AEE, et al. Effect of feed form, pellet diameter and enzymes supplementation on carcass characteristics, meat quality, blood plasma constituents and stress indicators of broilers. Arch Anim Breed 2014;57:30. https://doi.org/10.7482/0003-9438-57-030

29. Wondra KJ, Hancock JD, Kennedy GA, Hines RH, Behnke KC. Reducing particle size of corn in lactation diets from 1,200 to 400 micrometers improves sow and litter performance. J Anim Sci 1995;73:421-6. https://doi.org/10.2527/ $1995.732421 \mathrm{x}$

30. Amaral NO, Amaral LGM, Cantarelli VS, Fialho ET, Zangeronimo MG, Rodrigues PB. Influence of maize particle size on the kinetics of starch digestion in the small intestine of growing pigs. Anim Prod Sci 2015;55:1250-4. https://doi. org/10.1071/AN14050

31. Appel WB. Physical properties of feed ingredients. Feed manufacturing technology. Arlington, VA, USA: American Feed Industry Association Inc.; 1994. pp.151-2.

32. Kovalczyk T. Etiologic factors of gastric ulcers in swine. Am J Vet Res 1969;30:393-400.

33. Ramis G, Gomez S, Pallares, FJ, Munoz A. Influence of farm size on the prevalence of oesophagogastric lesions in pigs at slaughter in south-east Spain. Vet Rec 2004;155:210-3. https:// doi.org/10.1136/vr.155.7.210

34. Lawrence BV, Anderson DB, Adeola O, Cline TR. Fasting, transportation, and diet particle size influence development of stomach ulceration in pigs. West Lafayette, IN, USA: Purdue University; 1996. 